Postprint version. Original publication in:

Oecologia (2009) 159(3): 539-547

doi: 10.1007/s00442-008-1240-6

\title{
Larval parasitism of the autumnal moth reduces feeding intensity on the mountain birch
}

\author{
Tea Ammunét, Netta Klemola, Annette Heisswolf, Tero Klemola
}

Section of Ecology, Department of Biology, University of Turku, 20014 Turku, Finland

Received: 18 February 2008 / Accepted: 14 November 2008 / Published online: 10 December 2008 Communicated by Richard Karban.

\begin{abstract}
Plants respond to grazing by herbivorous insects by emitting a range of volatile organic compounds, which attract parasitoids to their insect hosts. However, a positive outcome for the host plant is a necessary precondition for making the attraction beneficial or even adaptive. Parasitoids benefit plants by killing herbivorous insects, thus reducing future herbivore pressure, but also by curtailing the feeding intensity of the still living, parasitised host. In this study, the effect of parasitism on food consumption of the 5th instar larvae of the autumnal moth (Epirrita autumnata) was examined under laboratory conditions. Daily food consumption, as well as the duration of the 5th instar, was measured for both parasitised and non-parasitised larvae. The results showed that parasitism by the solitary endoparasitoid Zele deceptor not only reduced leaf consumption significantly but also hastened the onset of pupation in autumnal moth larvae. On the basis of the results, an empirical model was derived to assess the affects on the scale of the whole tree. The model suggests that parasitoids might protect the tree from total defoliation at least at intermediate larval densities. Consequently, a potential for plant-parasitoid chemical signalling appears to exist, which seems to benefit the mountain birch (Betula pubescens ssp. czerepanovii) by reducing the overall intensity of herbivore defoliation due to parasitism by this hymenopteran parasitoid.
\end{abstract}

Keywords Epirrita autumnata $\cdot$ food consumption · tritrophic interactions · Zele deceptor

\section{INTRODUCTION}

Leaf consumption by herbivores induces a chemical reaction and release of inducible volatile organic compounds (VOCs) by the host plant (Turlings et al., 1990; De Moraes et al., 1998; Turlings \& Wäckers, 2004; Heil, 2008). VOCs can be utilised by predators and parasitoids as cues in host detection (e.g. Camors \& Payne, 1972; Price et al., 1980; Nealis, 1986; Turlings et al., 1990; De Moraes et al., 1998; Halitschke et al., 2008) and, consequently, they contribute to the reduction of herbivore pressure on the host plant 
(van Loon et al., 2000; Kessler \& Baldwin, 2001; Heil, 2008). This phenomenon, which describes the complex inter-specific interactions between herbivore-damaged plants, herbivores and natural enemies, is known as 'crying for help' (Turlings et al., 1990). Such a complex interaction between plants and natural enemies is, however, only likely if natural enemies sufficiently reduce herbivory to the extent that plant fitness increases despite the potential cost of chemical signalling (van der Meijden \& Klinkhamer, 2000; Fritzsche-Hoballah \& Turlings, 2001; Hoballah et al., 2004).

Although predators may be expected to decrease herbivore numbers immediately, the impact of parasitoids cannot be anticipated to be as straightforward. In many systems where parasitoids are able to considerably reduce the population size of their hosts (Bylund, 1995; Ferguson \& Stiling, 1996; Münster-Swendsen, 2002; Tanhuanpää et al., 2002), this impact will take effect only in the next generation of the herbivore and thus cannot be of immediate advantage to a plant that is 'crying for help'. Koinobiont parasitoids can, however, alter the physiology and behaviour, e.g. the developmental time and food consumption, of their still living and mobile hosts (Vinson \& Iwantsch, 1980; Harvey et al., 1994; Elzinga et al., 2003; Brodeur \& Boivin, 2004). Regarding herbivore food consumption, parasitoids can cause both stimulative, as well as restrictive effects, which seem to be related to their particular life history traits. Gregarious species, i.e. where several parasitoid larvae develop within/upon one host, are likely to increase the food consumption of their hosts (Slansky, 1986; Alleyne \& Beckage, 1997; Smallegange et al., 2008), whereas solitary species (one parasitoid larva per host) usually have the opposite effect (Guillot \& Vinson, 1973; Rohlfs \& Mack, 1983; Senthamizhselvan \& Muthukrishnan, 1989; Kumar \& Ballal, 1992; Harvey, 1996; Bae \& Kim, 2004). A few studies have already shown that parasitoid-induced diminished food consumption in herbivorous insects has led to increased plant fitness (van Loon et al., 2000; Fritzsche-Hoballah \& Turlings, 2001; Smallegange et al., 2008).

In northern Fennoscandia, in the tritrophic system consisting of mountain birches [Betula pubescens ssp. czerepanovii (Orlova) Hämet-ahti (Fagales: Betulaceae)], autumnal moths [Epirrita autumnata (Borkhausen) (Lepidoptera: Geometridae)] and their hymenopteran parasitoids, mountain birches occasionally suffer from elevated herbivore pressure. This is caused by the high amplitude and cyclic population fluctuations of autumnal moths, which can lead to severe large-scale forest defoliations (Tenow, 1972; Lehtonen, 1987; Haukioja et al., 1988; Klemola et al., 2002). During the density increase of the autumnal moth, predators are unable to effectively track the rapid changes in herbivore densities (Enemar et al., 1984; Ruohomäki et al., 2000). However, in both the peak and decline phases of the moth cycle, there are at least 15 hymenopteran parasitoid species present in high numbers, which attack either the egg, larval or pupal stages of E. autumnata (Tenow, 1972; Ruohomäki, 1994; Bylund, 
1995; Tanhuanpää et al., 2002; Klemola et al., 2007, 2008a,b). Of all parasitoids present, the proportion of solitary species is high (Klemola et al., 2007, 2008a). Thus, particularly solitary parasitoids could be the primary enemies of herbivores attracted to the VOCs produced by mountain birches after herbivore damage.

Indeed, damage due to autumnal moth feeding triggers the octadecanoid pathway and the production of VOCs in the mountain birch (Kaitaniemi et al., 1998; Riipi et al., 2002; Haukioja, 2005; Mäntylä et al., 2008a). As a further indication of the potential interactions between mountain birches and the natural enemies of the insect herbivores, mountain birches defoliated by sawflies and autumnal moths have been shown to attract passerine birds (Mäntylä et al., 2004, 2008a), while the defoliation of silver birches Betula pendula by autumnal moths seems to attract tits (Mäntylä et al., 2008b). However, neither the attractiveness of mountain birch VOCs to parasitoids, nor the effects of parasitoids on autumnal moth food consumption have been previously studied. To eventually reveal more complex tritrophic interactions between mountain birches, autumnal moths and their parasitoids, it is first necessary to elucidate the interactions between two trophic levels.

In this experiment, we examined whether parasitism by the solitary koinobiont parasitoid Zele deceptor Wesmael (Hymenoptera: Braconidae) affects feeding in the final 5th instar of autumnal moth larvae, when most of the food consumption occurs. Daily food intake and the duration of the 5th instar were measured in both parasitised and non-parasitised larvae. We predicted that parasitised larvae would show reduced food consumption compared to non-parasitised animals. In addition, we evaluated the net effect of a potential change in larval food intake on a whole mountain birch tree, using an empirical mathematical model.

\section{MATERIALS AND METHODS}

\section{The study species}

The autumnal moth is a medium-sized (wingspan ca 3-4 cm), cryptic, forest dwelling moth, whose adults eclose from mid-August onwards, the males actively seeking their less mobile mates. Females lay eggs on tree trunks, branches and shoots, where the eggs overwinter. The foliage-feeding larvae hatch in the spring. In northern Fennoscandia, the larvae experience five instars from late May to early July, and pupate in the soil.

The hymenopteran wasp Zele deceptor is a late larval endoparasitoid (attacking the 4th and 5th instar larvae), whose own larvae emerge from a prepupal stage of the autumnal moth and create their own white cocoon beside the perished host. The adult 
parasitoid is approximately $11 \mathrm{~mm}$ long, and females possess an ovipositor measuring $2 \mathrm{~mm}$ in length.

\section{Rearing of autumnal moth larvae}

The experiment was conducted in the summer of 2006 at the Kevo Subarctic Research Station $\left(69^{\circ} 45^{\prime} \mathrm{N}, 27^{\circ} 01^{\prime} \mathrm{E}\right), 80 \mathrm{~m}$ above sea level, in the Utsjoki municipality of northernmost Finland. Autumnal moth adults, collected as larvae from mountain birch forests in northern Norway and Finland, but not more than $100 \mathrm{~km}$ from Kevo, were either mated with each other or with adults of a laboratory strain from the autumn of 2005 and the eggs were stored. We raised a total of 280 larvae from seven broods. Neonate larvae were reared individually in transparent plastic vials of $48 \mathrm{ml}$ and raised in outdoor conditions until most had reached the 4 th instar, when they were transferred indoors. The larvae were supplied with fresh birch leaves at intervals of about 3 days.

Four of the seven broods were chosen according to the overall condition of the larvae and the number of 4th instar larvae of sufficient size. Six individuals from each of the four broods were randomly chosen as control larvae, with 12 chosen for exposure to parasitoids, giving a total of 24 control larvae and 48 exposed larvae. A higher number of larvae were used in the latter group because a $100 \%$ parasitism rate was not expected.

\section{Rearing of parasitoids}

Zele deceptor parasitoids were raised from parasitised autumnal moth larvae collected the previous year either from Norway or the Utsjoki area. Through the winter, Z. deceptor cocoons were kept in transparent plastic vials $(48 \mathrm{ml})$, half-filled with moist Sphagnum moss, in an outdoor storage with slightly warmer than ambient temperature conditions. In late spring, parasitoid cocoons were transferred indoors. Before the experiment, all adult parasitoids that emerged were kept at $15^{\circ} \mathrm{C}$ in $200 \mathrm{ml}$ transparent plastic vials, each containing a small birch twig and a strip of blotting paper soaked in a $30 \%$ honey-water solution for nourishment. Due to the paucity of female parasitoids, only four individuals were used in the experiment. However, no statistically significant differences in leaf consumption were found between the larvae parasitised by different females (data not shown).

\section{Parasitism}

Exposure to parasitism was conducted in four plastic containers $(18 \times 18 \times 10 \mathrm{~cm})$, each supplied with a strip of blotting paper soaked in a $30 \%$ honey-water solution. In each container, female parasitoids were allowed to mate with one randomly chosen 
male for 1 day, after which, parasitoids were returned to the $200 \mathrm{ml}$ vials. Thereafter, 124 th instar autumnal moth larvae were placed in the containers in their $48 \mathrm{ml}$ rearing vials but with the lids removed. Fresh birch leaves were provided as food both within the vials and on the bottom of the container. Finally, one female parasitoid was again released into each container to allow it to parasitise the subjected larvae for a period of $24 \mathrm{~h}$.

During parasitism exposures, all containers, including the control larvae in their rearing vials were kept at $15^{\circ} \mathrm{C}$. After exposure, larvae were removed from the containers and placed again in individual vials of $48 \mathrm{ml}$. At this point, the individual information of brood affiliation was lost for those larvae subjected to parasitism, because almost all larvae had moved out of their individual vials. All 72 experimental larvae in their vials were then placed in one $10 \times 10$ grid by randomly choosing a control larva and then a couple of larvae exposed to female parasitoids.

After rearing the larvae at room temperature for $24 \mathrm{~h}, 24$ larvae had begun to moult to their 5th and final instar. All moulting larvae were placed without any food in the corresponding identical positions in another grid at $5^{\circ} \mathrm{C}$ in a growth chamber to synchronise the start of the 5th instar. The remaining 48 larvae started moulting the following day and were placed at $5^{\circ} \mathrm{C}$ as soon as the moult was observed. When all larvae had started moulting, they were relocated to the growth chamber at $15^{\circ} \mathrm{C}$ to hasten moulting. After $36 \mathrm{~h}$, the larvae were transferred to room temperature to enable the start of the 5th instar. We began the controlled feeding experiment approximately $6 \mathrm{~h}$ later, when all larvae had reached the final instar.

\section{Feeding experiment}

The feeding experiment was carried out over 10 days. Vials were cleaned and two new birch leaves were supplied daily. Prior to feeding, the leaf fresh weight (mg) was measured using a digital scale. The leaves were then photographed and placed in water-filled $1 \mathrm{ml}$ plastic tubes. The leaf petioles were kept in place in the water with Parafilm. The tubes were placed inside the individual rearing vials. The following day, leaf remnants were weighed and photographed again. By repeating this procedure daily, feeding during the whole 5th larval instar was recorded for each larva. All birch leaves used during one day were taken from one large branch to minimise the variation in food quality.

On the first day of the experiment, all larvae were kept at $15^{\circ} \mathrm{C}$ for $24 \mathrm{~h}$, but due to low feeding activity, the temperature was raised to $20^{\circ} \mathrm{C}$ from the 2 nd day onwards. Larval leaf consumption was measured using two methods. Firstly, the difference in leaf area before and after $24 \mathrm{~h}$ of feeding was measured (in square millimetres) from photographs using the threshold colour-based method (macro: Threshold_colour, Lan- 
dini 2007) within the image analysis program WCIF ImageJ 1.37a (Rasband, 19972004). Secondly, the leaf mass consumed (mg) was calculated (adjusted by water evaporation of control leaves), which gave qualitatively very similar results to the leaf area measurements. However, as the leaf mass results were less accurate for small amounts of leaf consumption (Ammunét, 2007) and to avoid data redundancy, only the results of the areal measurements are presented here.

After 10 days, all experimental larvae had finished feeding. When a larva had entered the prepupal stage, its vial was cleaned and half-filled with moist Sphagnum moss, in which larvae would also pupate under natural conditions. Parasitised individuals were easily identified from their parasitoid cocoon approximately 10 days from the prepupal phase. Four of the parasitoids were unable to pupate properly and were identified from the remnants of the parasitoid larvae. Because not all subjected larvae were parasitised, two new groups were established. The group of larvae subjected to parasitism but not parasitised is hereafter referred to as 'exposed', while those that were successfully parasitised comprise the group 'parasitised'.

The overall parasitism rate was $62.5 \%$ (30 parasitised out of 48 ). Two control and one subjected larva died during the study, thus the final number of non-parasitised larvae (17 exposed and 22 control larvae) was 39. Larvae that died during the study were omitted from the statistical analyses.

\section{Mathematical modelling}

A simple, empirical mathematical model was constructed (Eq. 1) to extrapolate the results to the scale of the whole tree.

$$
f(x, y)=\frac{y[a(1-x)+b x]}{300}
$$

The model describes which proportion of leaves is eaten at different combinations of larval densities and parasitism rates, where $y$ is larval density and $x$ the parasitism rate. Larval density is given as the number of larvae per 300 leaves, because a range from 0 to 300 larvae per 100 short shoots (each typically with three leaves) has already been measured (Tenow et al., 2004; T. Klemola et al., unpublished data). The parasitism rate ranges from 0 to 100 (Bylund, 1995; Klemola et al., 2008a). For 5th instar larvae of the autumnal moth, the value $a$ is the total amount of leaves consumed by a non-parasitised larva, while $b$ is the total amount of leaves eaten by a parasitised individual. It is assumed that all parasitoids are solitary and have the same effect on the consumption of larvae as $Z$. deceptor in this experiment. 


\section{Statistical analysis}

All statistical analyses were conducted with SAS 9.1 statistical software. The effects of parasitism on leaf consumption were analysed with a general linear model with a repeated measures design (the MIXED procedure), using the restricted maximumlikelihood method. The treatments (parasitised, exposed and control), experiment days and their interaction were included as fixed effects. Pairwise comparisons between the daily leaf consumption of the different treatments were calculated using Tukey's test to minimise the probability of Type I errors. Degrees of freedom were counted with the Kenward-Rogers method, which is highly suitable for a conducted model (Kowalchuk et al., 2004). Experiment day was taken into account as a repeated effect where an individual larva was the subject effect. However, only the first 5 days of the study were included in the analyses of daily leaf consumption, because afterwards many larvae had already entered the prepupal stage and thus the number of still feeding larvae decreased sharply.

Model selection, based on Akaike information criteria and Akaike weights, was applied regarding the variance-covariance structure of the repeated effect (Wolfinger, 1993; Little et al., 1996; Burnham \& Anderson, 2002). Based on the results of model selection, the heterogeneous first-order autoregressive (ARH1) model was chosen.

The differences between treatments based on total leaf consumption during the whole 5th instar were analysed with a general linear model (the GLM procedure). The total consumption value for each larva was calculated by summing daily consumption values. The total number of leaves consumed daily was calculated by dividing the total area consumed by the average size of the leaves each day.

The effects of parasitism on the duration of the 5th instar were analysed using the exact likelihood ratio chi-squared test (the FREQ procedure); asymptotic tests might not be accurate due to the small sample size.

The effect of larval sex on total leaf consumption was analysed with a general linear model (the GLM procedure). As moth sex was determined from the pupa and the effect of brood was also included in the model, this analysis was made for the control larvae only.

\section{RESULTS}

The amount of leaf area consumed during the experiment varied significantly between the three treatments (control, exposed, parasitised) (Treatment: $F_{2,106}=73.20, P<$ 0.0001; Treatment $\times$ Experiment day: $F_{8,175}=5.97, P<0.0001$ ). Parasitised larvae consumed significantly less leaves than exposed or control larvae on the 3rd day and onwards (Fig. 1, Table 1). On the 1st day of the experiment, leaf consumption did not 
differ between treatments, while on the 2nd day parasitised and exposed treatments showed no significant differences (Fig. 1, Table 1).

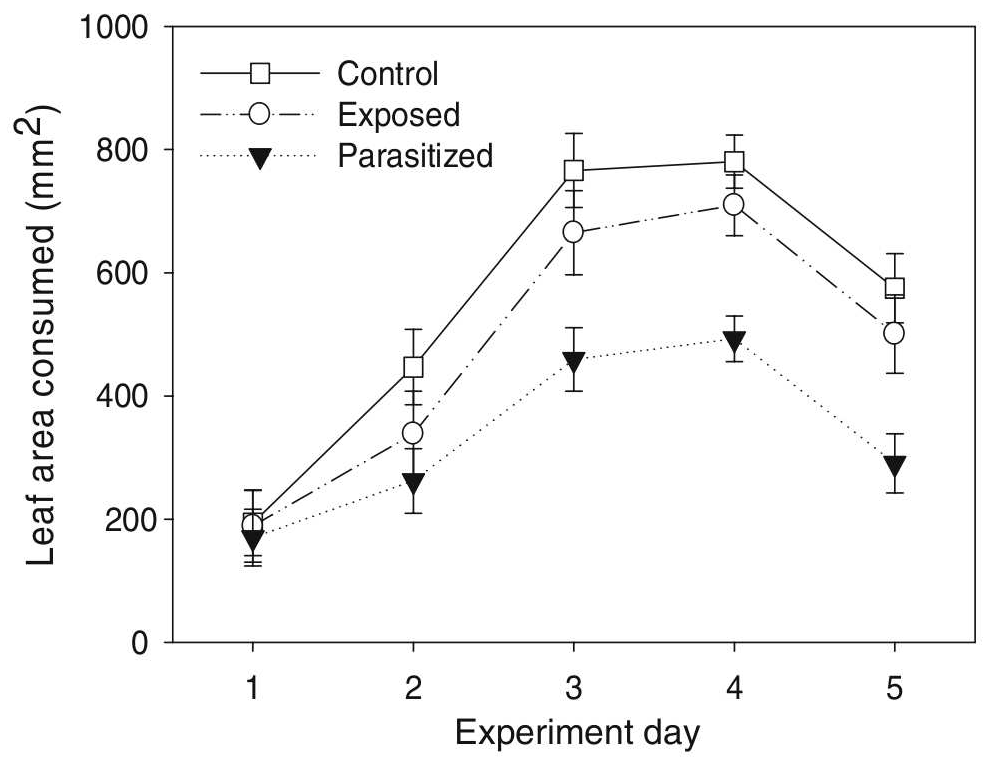

Fig. 1 Leaf area consumed per day by autumnal moth larvae during the first 5 days of the feeding experiment in the three treatment groups (control, exposed and parasitised). Least squares means with 95\% confidence intervals are presented from the statistical model described in the text.

Table 1 A posteriori pairwise comparisons of leaf consumption between the three treatments (control, exposed, parasitised) for the first 5 days of the feeding experiment. $t$ - and $P$-values of Tukey's test are given for each comparison.

\begin{tabular}{lrrr}
\hline Treatment comparison & Day & $t$ & $P$ \\
\hline Parasitised versus exposed & 1 & 0.50 & 0.6156 \\
& 2 & 1.75 & 0.0842 \\
& 3 & 4.80 & $<0.0001$ \\
& 4 & 7.01 & $<0.0001$ \\
Parasitised versus control & 5 & 5.26 & $<0.0001$ \\
& 1 & 0.68 & 0.5017 \\
& 2 & 4.59 & $<0.0001$ \\
& 3 & 7.74 & $<0.0001$ \\
Control versus exposed & 4 & 10.06 & $<0.0001$ \\
& 5 & 7.70 & $<0.0001$ \\
& 1 & 0.13 & 0.9009 \\
& 2 & 2.34 & 0.0222 \\
& 3 & 2.21 & 0.0302 \\
& 4 & 2.15 & 0.0348 \\
& 5 & 1.75 & 0.0846 \\
\hline
\end{tabular}

The respective mean values are plotted in Fig. 1.

The overall leaf consumption during the 5th instar was smallest for parasitised larvae (pairwise comparison with Tukey adjustment: $P<0.0001$ for both parasitised 
versus control and parasitised versus exposed larvae, Fig. 2). No significant difference was observed between control and exposed larvae $(P=0.95$, Fig. 2$)$. When converted to leaves eaten, both control (least squares mean $\pm 95 \% \mathrm{CL}: 3.14 \pm 0.39$ ) and exposed (3.07 \pm 0.33$)$ larvae ate on average one leaf more than parasitised (1.94 \pm 0.13$)$ larvae during the 5 th instar.

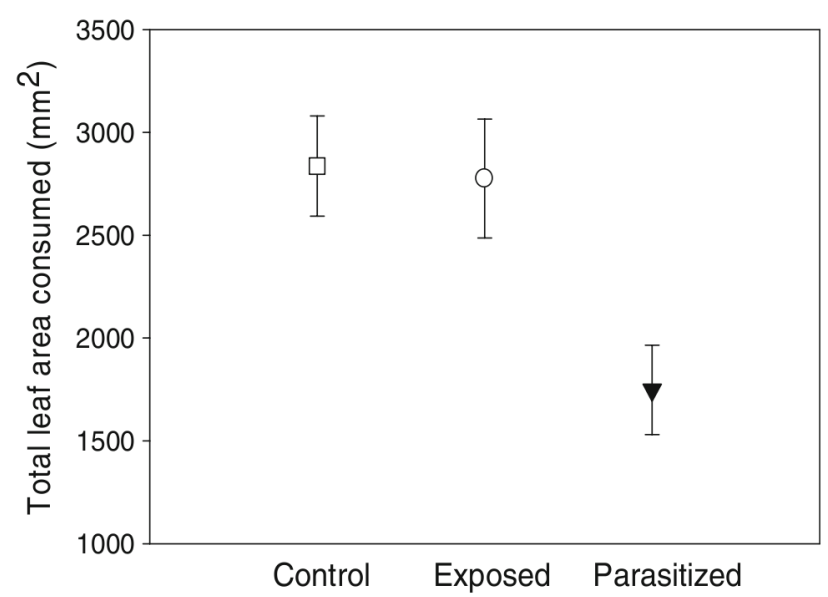

Fig. 2 Total leaf area consumed by autumnal moth larvae during the 5th instar in the three treatment groups (control, exposed and parasitised). Least squares means with 95\% confidence intervals are presented. The number of larvae in each group is indicated above the symbols.

Of the total amount of leaves eaten, values of 3.1 and 1.9 leaves for parameters $a$ and $b$, respectively, were retrieved from the mathematical model, according to which an increase in parasitism rate prevents complete defoliation at intermediate larval densities, but has no effect at the highest densities, when the trees are totally defoliated, irrespective of the parasitism rate (Fig. 3).

The duration of the 5th instar was shorter for parasitised than either control or exposed larvae $\left(\chi_{8}^{2}=40.85, P<0.0001\right)$, with parasitised larvae commencing pupation approximately 1 day before either of the other groups. In addition, $90 \%$ of the parasitised larvae had already entered the prepupal stage on the 7th day of the experiment, compared to only $40 \%$ and $30 \%$ of the exposed and control larvae, respectively (Fig. 4)

The sex of the control larvae affected the total amount of leaf consumed $\left(F_{1,15}=\right.$ $29.02, P<0.0001)$. In total, females consumed a larger leaf area than males, with a mean difference of $743.9 \mathrm{~mm}^{2}$ or approximately $79 \%$ of one leaf. This was expected because females (also as pupae) are typically heavier than males (e.g. Tammaru et al., 2000).

The brood of the control larvae did not have a significant effect on total leaf consumption (Brood: $F_{3,15}=0.80, P=0.51$; Brood $\times$ Sex: $F_{3,15}=0.62, P=0.55$ ). Thus, there were probably no genetic differences that could have affected leaf consumption. Accordingly, that the initial information on brood identity had been lost during the sub- 


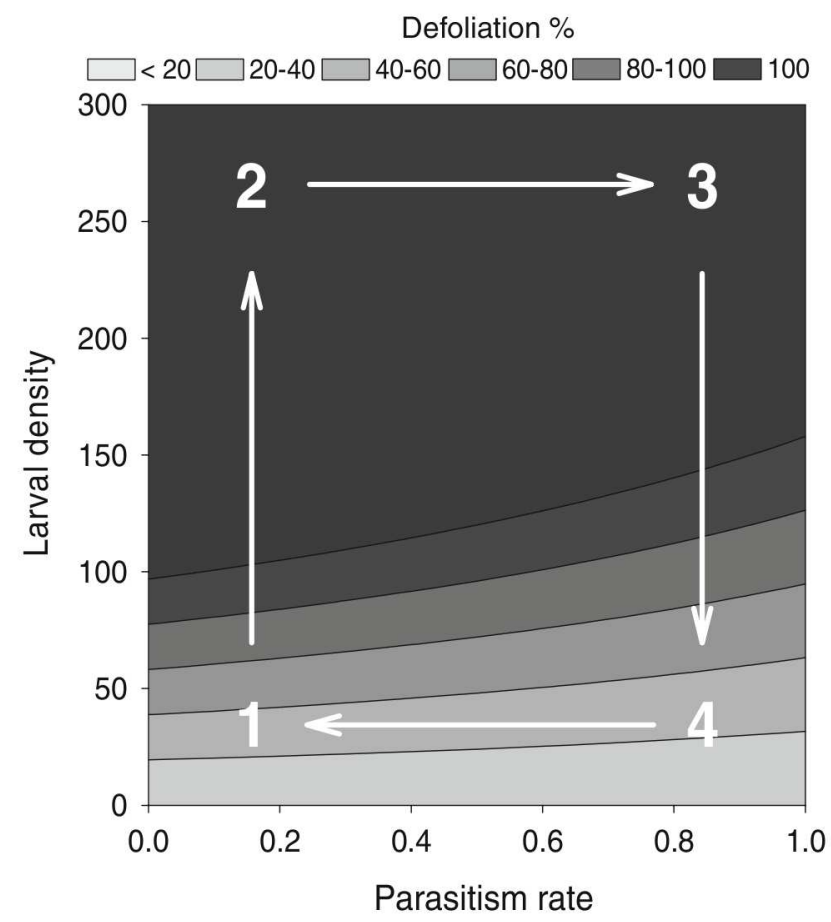

Fig. 3 Model-based result of leaf defoliation at different larval densities (no. of larvae per 100 short shoots) and larval parasitism rate. The numbers illustrate the areas of combinations of larval densities and parasitism rates that can be observed in the successive stages of the hypothetical moth cycle: 1 moth density still on the lowest level or just about to increase, parasitism rates low; 2 moth density still increasing or has just reached the outbreak level, parasitism rates still low; 3 moth density still at outbreak levels or just starting to decrease, parasitism rates high; 4 moth density still decreasing or just reaching the lowest level, parasitism rates still high. The order and the direction of the hypothetical moth cycle are illustrated with arrows.

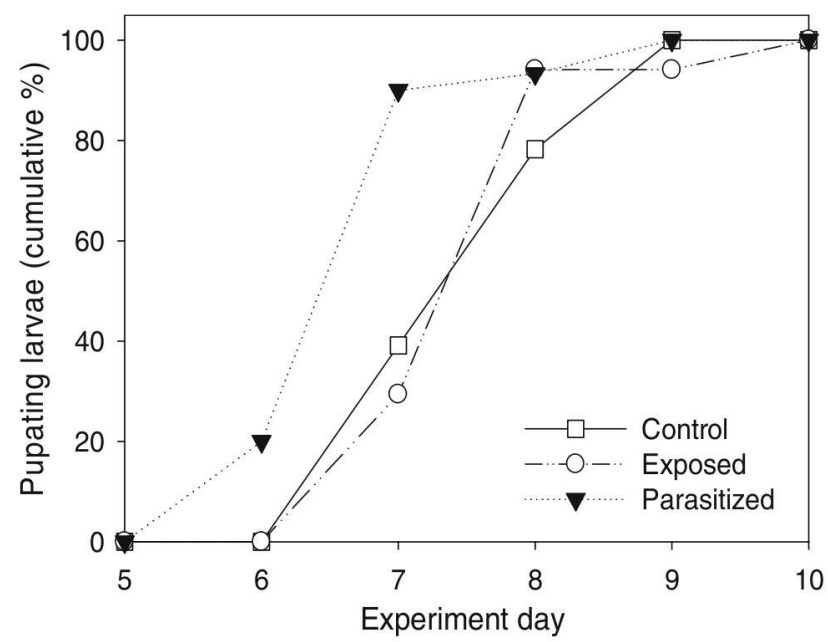

Fig. 4 Timing of pupation of 5th instar autumnal moth larvae. The plot shows the cumulative proportion of larvae that pupated in each treatment group (control, exposed and parasitised) during the last 5 days of the experiment. 
jection to parasitoids for both exposed and parasitised larvae probably did not affect the main results of the experiment.

\section{Discussion}

Our experimental results reveal that parasitised autumnal moth larvae consumed significantly fewer leaves than those free of parasitoids: parasitism reduced the overall leaf consumption of a 5th instar larva by approximately one mountain birch leaf. Furthermore, parasitism clearly reduced the duration of the 5th instar of the autumnal moth. When these results are extrapolated to larval densities and parasitism rates observed in the field, the results of our mathematical model showed that an increase in parasitism rate lessens leaf damage at low larval densities and prevents the tree from being totally defoliated at intermediate larval densities, but is no longer effective during the highest larval densities recorded during autumnal moth outbreaks (Fig. 3).

Previous studies under laboratory conditions showed that non-parasitised autumnal moth larvae consume two to three birch leaves during their development (Haukioja \& Niemelä, 1974). In nature, feeding damages more leaves, because larvae do not consume leaves entirely but frequently move to a different leaf after a few bites (personal observation). As most of the consumption of the autumnal moth during its lifespan takes place during the relatively short period of the final instar (Haukioja \& Niemelä, 1974), parasitised larvae would also seem to suffer significantly reduced life-time consumption. Hence, the results of our model can be extended rather well to represent the whole larval lifespan.

In post-peak and decline phases of the autumnal moth cycle, the overall larval parasitism rates are noticeably high, occasionally approaching $100 \%$, of which a major proportion (>90\%) can be caused by solitary parasitoids (Bylund, 1995; Tanhuanpää et al., 2002; Klemola et al., 2007, 2008a; K. Ruohomäki and T. Klemola, unpublished data). According to our model, the reduction in food consumption owing to parasitoids may be enough to reduce the defoliation during the decline phase when the parasitism rate is high, but seems to be ineffective at the peak phase when larvae can cause total defoliation. This has also been observed in nature, where mountain birch forests have been totally defoliated and the effect of parasitism can be seen only after a delay (Tenow, 1972; Bylund, 1995; Klemola et al., 2004). However, only some autumnal moth populations reach outbreak levels in northern Fennoscandia (e.g. Klemola et al., 2007), further underpinning the ecological significance of reduced leaf damage due to larval parasitism.

Even a slight defoliation has been observed to provoke reduced shoot survivorship and reproduction of the mountain birch (Tuomi et al., 1989; Ruohomäki et al., 1997). 
Therefore, the observed reduction of defoliation by parasitism can truly have a positive effect on fitness-related traits, although lifespan fitness is very difficult to determine in the long-lived mountain birch. The reduction of herbivory to a level low enough to be beneficial for the plant is an important prerequisite for making potential chemical signalling adaptive between the first and third trophic levels (Dicke \& van Loon, 2000; van der Meijden \& Klinkhamer, 2000). Thus, it seems that this condition can be met in the system studied, as shown previously in other species (van Loon et al., 2000; Fritzsche-Hoballah \& Turlings, 2001; Smallegange et al., 2008).

In contrast to parasitoids, larval predators (mainly birds and some invertebrate generalists) seem to be limited more by factors other than autumnal moth density. As a consequence, they are often unable to effectively respond to the number of larvae at the peak phase of the moth population cycle (Enemar et al., 1984; Ruohomäki et al., 2000), which makes parasitoids the more important participants in the tritrophic interaction between mountain birches, autumnal moths and their natural enemies.

In addition to the reduced consumption observed in parasitised larvae, some decrease in daily consumption was also noted in the exposed group. This might be due to the fact that exposed and parasitised larvae were kept in the same container with conspecifics during the subjection to parasitoids. Living in groups has been observed to affect the size of the autumnal moth and thus probably also leaf consumption (Tammaru et al., 2000; Ruohomäki et al., 2003), even if experienced only for a short period of time. Thus, a slight crowding effect may show in both the parasitised and the exposed groups. However, this did not interfere with our main results, as the most meaningful comparison was seen between parasitised and exposed larvae, which had an identical rearing history but differed only in their fate of being parasitised or not. Furthermore, the total leaf consumption of the exposed larvae did not differ from control larvae.

In addition to the positive effects for the host plant, parasitoids themselves may also benefit from the reduced food consumption and feeding time of their herbivore host. The 5th instar autumnal moth larva provides more resources than needed for the development of $Z$. deceptor larva (personal observation). When the host is not wholly consumed, accelerating its development time should be favoured by the parasitoid, thereby decreasing the risk of feeding on decaying and infective tissue (Godfray, 1994, but see Slansky, 1986; Harvey, 1996; van der Meijden \& Klinkhamer, 2000). Secondly, the parasitoid has to cope with potentially toxic allelochemicals originating from the host plant (Slansky, 1986; Haukioja et al., 1988; Haukioja, 2003). Finally, as long as the parasitoid is still inside a living larva upon the tree, it faces many risks including predation as well as hyper- and superparasitism (Abrams \& Rowe, 1996; Harvey \& Strand, 2002). As shown by Tanhuanpää et al. (1999), pupal parasitism and predation rates are often relatively low, and thus it might be safer for the parasitoid to descend 
to the ground and pupate in the soil as soon as possible (Tanhuanpää et al., 1999; Tammaru et al., 2001).

Being beneficial for both the parasitoid and the host plant, it seems that the observed reduction in the food consumption of parasitised autumnal moth larvae could mediate a multitrophic interaction between mountain birches and parasitoids in the system studied. Parasitoids seem to be capable of reducing herbivore pressure by decreasing the herbivore population density not only in the next generation, but also by reducing immediate leaf consumption at low and intermediate larval densities. Although the effects of only a single solitary endoparasitoid on leaf consumption of Epirrita autumnata larvae were studied, we propose that the results of our study can, with certain precautions, be extrapolated to other solitary parasitoid species of the autumnal moth, many of which have also been observed to decrease the food intake of their host (Guillot \& Vinson, 1973; Senthamizhselvan \& Muthukrishnan, 1989; Harvey, 1996). Nevertheless, the combined effects of all 10-15 solitary and at least 1 gregarious parasitoid species should be analysed to investigate more specifically the consequences of parasitoid host manipulation for the host plant.

In conclusion, parasitism by $Z$. deceptor significantly reduced the amount and duration of feeding of autumnal moth larvae, which is in accordance with previous studies in other systems (Vinson \& Iwantsch, 1980; Rohlfs \& Mack, 1983; Senthamizhselvan \& Muthukrishnan, 1989; Bae \& Kim, 2004). The fact that both host plant and parasitoid seem to benefit from this effect might be the basis for a chemical communication between the two trophic levels, e.g. via VOCs. Thus, analysing the attractiveness of herbivore-induced VOC emissions to parasitoids will be the next step in further revealing multitrophic interactions within this system.

\section{ACKNOWLEDGEMENTS}

We would like to thank Tommi Andersson, Saara Koutaniemi, Kukka Kyrö, Juha Leino, Aino Luukkonen, Kati Miettinen, Taina Nyman, Kirsi Reponen and Kai Ruohomäki for helping with the experiment. We also thank Kevin O'Brien, Lauri Oksanen, the $\mathrm{PhD}$ students of the section of ecology, and two anonymous referees for their valuable comments. We are furthermore grateful to Kevo Subarctic Research Station for providing the facilities. This study was supported financially by the Academy of Finland (project 111195 to T. K.). The experiment performed complies with the current laws of Finland. 


\section{REFERENCES}

Abrams, P. A. \& Rowe, L. (1996). The effects of predation on the age and size of maturity of prey. Evolution 50: 1052-1061.

Alleyne, M. \& Beckage, N. E. (1997). Parasitism-induced effects on host growth and metabolic efficiency in tobacco hornworm larvae parasitized by Cotesia congregata. Journal of Insect Physiology 43: 407424.

Ammunét, T. (2007). Larval parasitism of autumnal moth reduces defoliation intensity of mountain birch. Master's thesis, Department of Biology, University of Turku, Finland.

Bae, S. \& Kim, Y. (2004). Host physiological changes due to parasitism of a braconid wasp, Cotesia plutellae, on diamondback moth, Plutella xylostella. Comparative Biochemistry and Physiology Part A: Molecular \& Integrative Physiology 138: 39-44.

Brodeur, J. \& Boivin, G. (2004). Functional ecology of immature parasitoids. Annual Review of Entomology 49: 27-49.

Burnham, K. P. \& Anderson, D. R. (2002). Model selection and multi-model inference: a practical information-theoretic approach. Springer, New York.

Bylund, H. (1995). Long-term interactions between the autumnal moth and mountain birch: the roles of resources, competitors, natural enemies, and weather. Ph.D. thesis.

Camors, F. B. \& Payne, T. L. (1972). Response of Heydenia unica (Hymenoptera-Pteromalidae) to Dendroctonus frontalis (Coleoptera-Scolytidae) pheromones and a host-tree terpene. Annals of the Entomological Society of America 65: 31-33.

De Moraes, C. M., Lewis, W. J., Paré, P. W., Alborn, H. T. \& Tumlinson, J. H. (1998). Herbivore-infested plants selectively attract parasitoids. Nature 393: 570-573.

Dicke, M. \& van Loon, J. J. A. (2000). Multitrophic effects of herbivore-induced plant volatiles in an evolutionary context. Entomologia Experimentalis et Applicata 97: 237-249.

Elzinga, J. A., Harvey, J. A. \& Biere, A. (2003). The effects of host weight at parasitism on fitness correlates of the gregarious koinobiont parasitoid Microliptis tristis and consequences for food consumption by its host, Hadena bicruris. Entomologia Experimentalis et Applicata 108: 95-106.

Enemar, A., Nilsson, L. \& Sjöstrand, B. (1984). The composition and dynamics of the passerine bird community in a subalpine birch forest, Swedish Lapland. A 20-year study. Annales Zoologici Fennici 21: $321-338$.

Ferguson, K. I. \& Stiling, P. (1996). Non-additive effects of multiple natural enemies on aphid populations. Oecologia 108: $375-379$.

Fritzsche-Hoballah, M. E. \& Turlings, T. C. J. (2001). Experimental evidence that plants under caterpillar attack may benefit from attracting parasitoids. Evolutionary Ecology Research 3: 553-565.

Godfray, H. C. J. (1994). Parasitoids: behavioural and evolutionary ecology. Princeton University Press, Princeton, NJ.

Guillot, F. S. \& Vinson, S. B. (1973). Effect of parasitism by Cardiochiles nigriceps on food consumption and utilization by Heliothis virescens. Journal of Insect Physiology 19: 2073-2082.

Halitschke, R., Stenberg, J. A., Kessler, D., Kessler, A. \& Baldwin, I. T. (2008). Shared signals - 'alarm calls' from plants increase apparency to herbivores and their enemies in nature. Ecology Letters 11: 24-34.

Harvey, J. A. (1996). Venturia canescens parasitizing Galleria mellonella and Anagasta kuehniella: is the parasitoid a conformer or regulator? Journal of Insect Physiology 42: 1017-1025. 
Harvey, J. A., Harvey, I. F. \& Thomson, D. J. (1994). Flexible larval growth allows use of a range of host sizes by a parasitoid wasp. Ecology 75: 1420-1428.

Harvey, J. A. \& Strand, M. R. (2002). The developmental strategies of endoparasitoid wasps vary with host feeding. Ecology 83: 2439-2451.

Haukioja, E. (2003). Putting the insect into the birch-insect interaction. Oecologia 136: 161-168.

Haukioja, E. (2005). Plant defenses and population fluctuations of forest defoliators: mechanism-based scenarios. Annales Zoologici Fennici 42: 313-325.

Haukioja, E., Neuvonen, S., Hanhimäki, S. \& Niemelä, P. (1988). The autumnal moth in Fennoscandia. In: Berryman, A. A. (ed.) Dynamics of Forest Insect Populations: Patterns, Causes, and Implications, Plenum Press, New York, pp. 163-178.

Haukioja, E. \& Niemelä, P. (1974). Growth and energy requirements of the larvae of Dineura virididorsata (Retz.) (Hym., Tenthredinidae) and Oporinia autumnata (Bkh.) (Lep., Geometridae) feeding on birch. Annales Zoologici Fennici 11: 207-211.

Heil, M. (2008). Indirect defence via tritrophic interactions. New Phytologist 178: 41-61.

Hoballah, M. E., Köllner, T. G., Degenhardt, J. \& Turlings, T. C. J. (2004). Costs of induced volatile production in maize. Oikos 105: 168-180.

Kaitaniemi, P., Ruohomäki, K., Ossipov, V., Haukioja, E. \& Pihlaja, K. (1998). Delayed induced changes in the biochemical composition of host plant leaves during an insect outbreak. Oecologia 116: 182190.

Kessler, A. \& Baldwin, I. T. (2001). Defensive function of herbivore-induced plant volatile emissions in nature. Science 291: 2141-2144.

Klemola, N., Kapari, L. \& Klemola, T. (2008a). Host plant quality and defence against parasitoids: no relationship between levels of parasitism and a geometrid defoliator immunoassay. Oikos 117: 926934.

Klemola, T., Andersson, T. \& Ruohomäki, K. (2008b). Fecundity of the autumnal moth depends on pooled geometrid abundance without a time lag: implications for cyclic population dynamics. Journal of Animal Ecology 77: 597-604.

Klemola, T., Klemola, N., Andersson, T. \& Ruohomäki, K. (2007). Does immune function influence population fluctuations and level of parasitism in the cyclic geometrid moth? Population Ecology 49: $165-178$.

Klemola, T., Ruohomäki, K., Andersson, T. \& Neuvonen, S. (2004). Reduction in size and fecundity of the autumnal moth, Epirrita autumnata, in the increase phase of a population cycle. Oecologia 141: $47-56$.

Klemola, T., Tanhuanpää, M., Korpimäki, E. \& Ruohomäki, K. (2002). Specialist and generalist natural enemies as an explanation for geographical gradients in population cycles of northern herbivores. Oikos 99: 83-94.

Kowalchuk, R. K., Keselman, K. J., Algina, J. \& Wolfinger, R. D. (2004). The analysis of repeated measurements with mixed-model adjusted F tests. Educational and Psychological Measurement 64: 224-242.

Kumar, P. \& Ballal, C. R. (1992). The effect of parasitism by Hyposotera didymator [Hym.: Ichneumonidae] on food consumption and utilization by Spodoptera litura [Lep.: Noctuidae]. Entomophaga 37: 197-203.

Landini, G. (2007). Threshold_colour. Version 1.8. URL http://www.dentistry.bham.ac.uk/ landinig/sof tware/sof tware.html. 
Lehtonen, J. (1987). Recovery and development of birch forests damaged by Epirrita autumnata in Utsjoki area, North Finland. Reports from the Kevo Subarctic Research Station 20: 35-39.

Little, R. C., Milliken, G. A., Stroup, W. W. \& Wolfinger, R. D. (1996). SAS system for mixed models. SAS Institute Inc, Cary, NC.

Mäntylä, E., Alessio, G. A., Blande, J. D., Heijari, J., Holopainen, J. K., Laaksonen, T., Piirtola, P. \& Klemola, T. (2008a). From plants to birds: higher avian predation rates in trees responding to insect herbivory. PLOS ONE 3: e2832.

Mäntylä, E., Klemola, T. \& Haukioja, E. (2004). Attraction of willow warblers to sawfly-damaged mountain birches: novel function of inducible plant defences? Ecology Letters 7: 915-918.

Mäntylä, E., Klemola, T., Sirkiä, P. \& Laaksonen, T. (2008b). Low light reflectance may explain the attraction of birds to defoliated trees. Behavioral Ecology 19: 325-330.

Münster-Swendsen, M. (2002). The role of insect parasitoids in population cycles of the spruce needleminer in Denmark. In: Berryman, A. A. (ed.) Population cycles: the case for trophic interactions, Oxford University Press, New York, pp. 29-43.

Nealis, V. G. (1986). Responses to host kairomones and foraging behavior of the insect parasite Cotesia rubecula (Hymenoptera, Braconidae). Ecological Entomology 64: 2393-2398.

Price, P. W., Bouton, C. E., Gross, P., McPheron, B. A., Thompson, J. N. \& Weis, A. E. (1980). Interactions among three trophic levels: Influence of plants on interactions between insect herbivores and natural enemies. Annual Review of Ecology and Systematics 11: 41-65.

Rasband, W. S. (1997-2004). Image J. National Institutes of Health, Bethesda. MD, URL http: //rsb. info.nih.gov/ij/.

Riipi, M., Ossipov, V., Lempa, K., Haukioja, E., Koricheva, J., Ossipova, S. \& Pihlaja, K. (2002). Seasonal changes in birch leaf chemistry: are there trade-offs between leaf growth and accumulation of phenolics? Oecologia 130: 380-390.

Rohlfs, W. M. \& Mack, T. P. (1983). Effect of parasitization by Ophion flavidus brulle (Hymenoptera: Ichneumonidae) on consumption and utilization of a pinto bean diet by fall armyworm (Lepidoptera: Noctuidae). Environmental Entomology 12: 1257-1259.

Ruohomäki, K. (1994). Larval parasitism in outbreaking and non-outbreaking populations of Epirrita autumnata (Lepidoptera, Geometridae). Entomologica Fennica 5: 27-34.

Ruohomäki, K., Klemola, T., Kaitaniemi, P. \& Käär, M. (2003). Crowding-induced responses in a geometrid moth revisited: a field experiment. Oikos 103: 489-496.

Ruohomäki, K., Tanhuanpää, M., Ayres, M. P., Kaitaniemi, P., Tammaru, T. \& Haukioja, E. (2000). Causes of cyclicity of Epirrita autumnata (Lepidoptera, Geometridae): grandiose theory and tedious practice. Population Ecology 42: 211-223.

Ruohomäki, K., Virtanen, T., Kaitaniemi, P. \& Tammaru, T. (1997). Old mountain birches at high altitudes are prone to outbreaks of Epirrita autumnata (Lepidoptera: Geometridae). Environmental Entomology 26: $1096-1104$

Senthamizhselvan, M. \& Muthukrishnan, J. (1989). Effect of parasitization by a gregarious and a solitary parasitoid on food consumption and utilization by Porthesia scintillans Walker (Lepidoptera: Lymantriidae) and Spodoptera exigua Hubner (Lepidoptera: Noctuidae). Parasitology Research 76: $166-170$.

Slansky, F. J. (1986). Nutritional ecology of endoparasitic insects and their hosts: an overview. Journal of Insect Physiology 32: 255-261. 
Smallegange, R. C., van Loon, J. J. A., Blatt, S. E., Harvey, J. A. \& Dicke, M. (2008). Parasitoid load affects plant fitness in a tritrophic system. Entomologia Experimentalis et Applicata 128: 172-183.

Tammaru, T., Ruohomäki, K. \& Montola, M. (2000). Crowding-induced plasticity in Epirrita autumnata (Lepidoptera: Geometridae): weak evidence of specific modifications in reaction norms. Oikos 90: 171-181.

Tammaru, T., Tanhuanpää, M., Ruohomäki, K. \& Vanatoa, A. (2001). Autumnal moth - why autumnal? Ecological Entomology 26: 646-654.

Tanhuanpää, M., Ruohomäki, K., Kaitaniemi, P. \& Klemola, T. (1999). Different impact of pupal predation on populations of Epirrita autumnata (Lepidoptera; Geometridae) within and outside the outbreak range. Journal of Animal Ecology 68: 562-570.

Tanhuanpää, M., Ruohomäki, K., Turchin, P., Ayres, M. P., Bylund, H., Kaitaniemi, P., Tammaru, T. \& Haukioja, E. (2002). Population cycles of the autumnal moth in Fennoscandia. In: Berryman, A. A. (ed.) Population Cycles: The Case for Trophic Interactions, Oxford University Press, New York, pp. $142-154$.

Tenow, O. (1972). The outbreaks of Oporinia autumnata Bkh. and Operophthera spp. (Lep., Geometridae) in the Scandinavian mountain chain and northern Finland 1862-1968. Zoologiska Bidrag från Uppsala, Supplement 2: 1-107.

Tenow, O., Bylund, H., Karlsson, P. S. \& Hoogesteger, J. (2004). Rejuvenation of a mountain birch forest by an Epirrita autumnata (Lepidoptera: Geometridae) outbreak. Acta Oecologia 25: 43-52.

Tuomi, J., Vuorisalo, T., Niemelä, P. \& Haukioja, E. (1989). Effects of localized defoliations on female inflorescences in mountain birch, Betula pubescens ssp. tortuosa. Canadian Journal of Botany 67: 334-338.

Turlings, T. C. J., Tumlinson, J. H. \& Lewis, W. J. (1990). Exploitation of herbivore-induced plant odors by host-seeking parasitic wasps. Science 250: 1251-1253.

Turlings, T. C. J. \& Wäckers, F. (2004). Recruitment of predators and parasitoids by herbivore-injured plants. In: Cardé, R. T. \& Millar, J. G. (eds.) Advances in Insect Chemical Ecology, Cambridge Universtiy Press, Cambridge, pp. 21-75.

van der Meijden, E. \& Klinkhamer, P. G. L. (2000). Conflicting interests of plants and the natural enemies of herbivores. Oikos 89: 202-208.

van Loon, J. J. A., de Boer, J. G. \& Dicke, M. (2000). Parasitoid-plant mutualism: parasitoid attack of herbivore increases plant reproduction. Entomologia Experimentalis et Applicata 97: 219-227.

Vinson, S. B. \& Iwantsch, G. F. (1980). Host regulation by insect parasitoids. The Quarterly Review of Biology 55: 143-165.

Wolfinger, R. D. (1993). Covariance structure selection in general mixed models. Communications in Statistics - Simulation and Computation 22: 1079-1106. 